بررسى ويزَّى ضدميكروبى فيلم خوراكى دولايه زلاتين - صمغ كُندر داراى اسيدآسكوربيك و اسانس زوفا (Hyssopus officinalis) بر زمان ماندكارى فيله شتر مرغ در دماى يخجال

مطهره بيرنيا 1'، فريده طباطبايى يزدى 2* سيد على مر تضوى 3 م محبت محبى 4

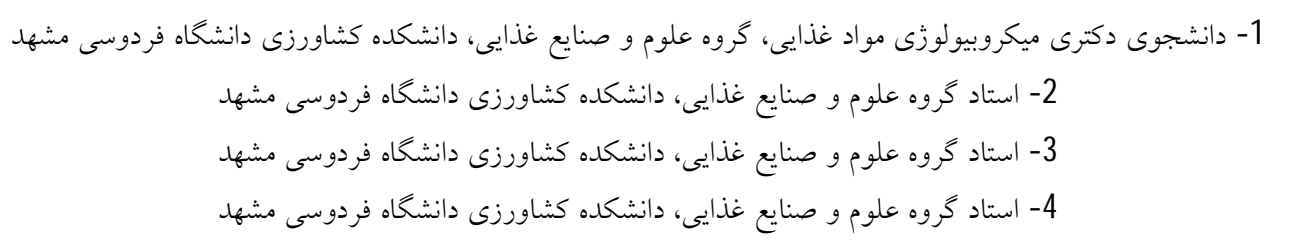

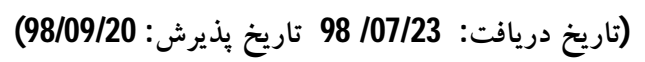

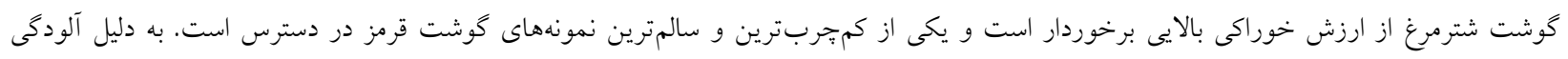

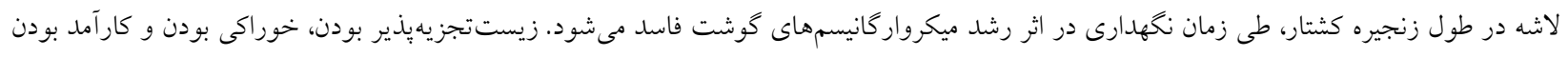

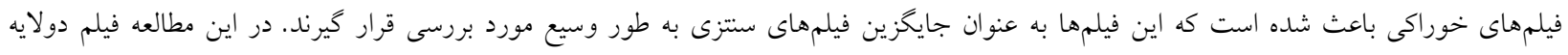

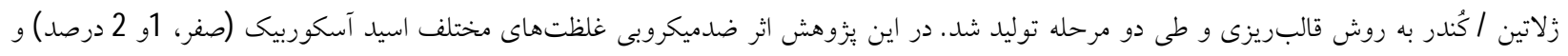

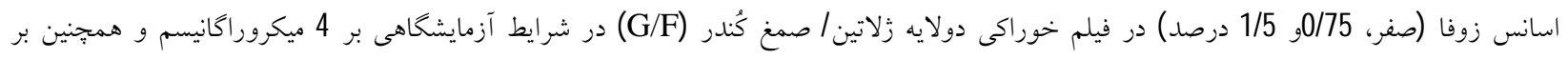

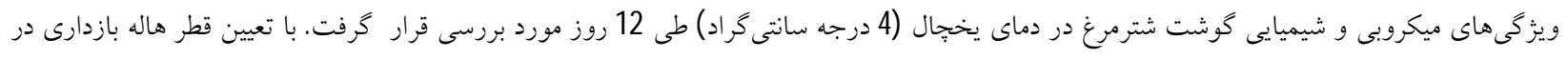

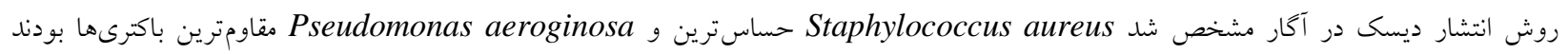

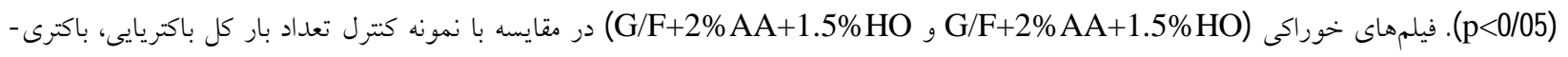

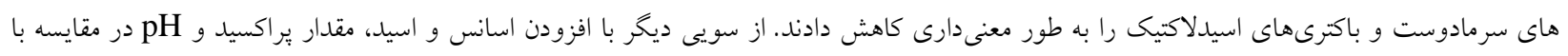

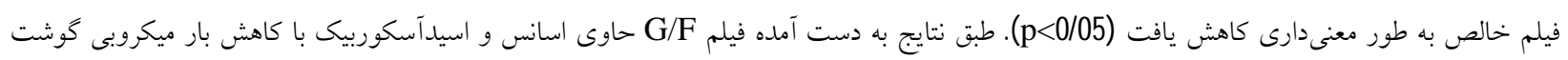

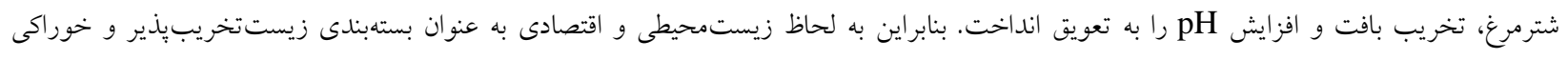

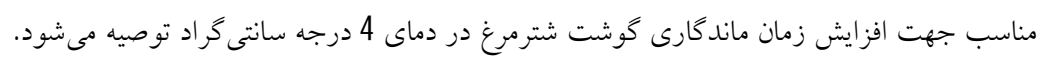
كليد وازگًان: فيلم خوراكى دولايه، صمغ كياه كُندر، اسانس زوفا، فعاليت ضدميكروبى، فيله شترمغ 
نمىباشند [9]. روشهاى مختلفى از جمله استفاده از فناورى نانو 1

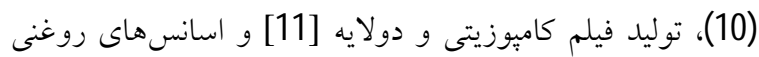

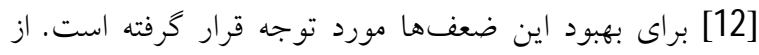

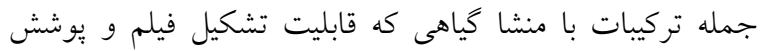

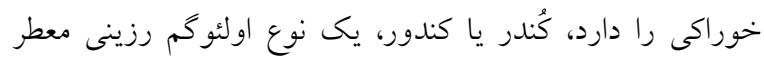

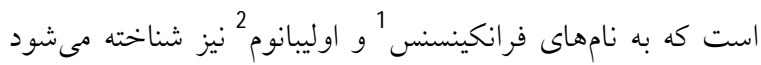

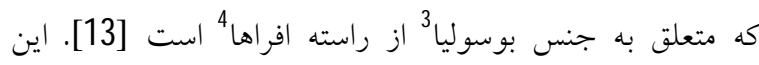

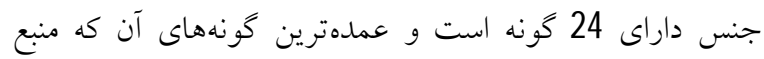

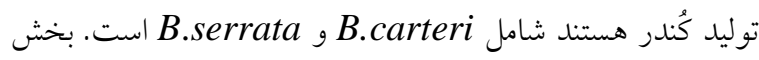

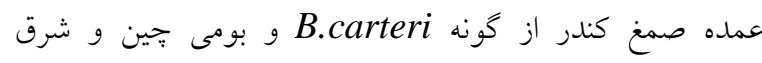

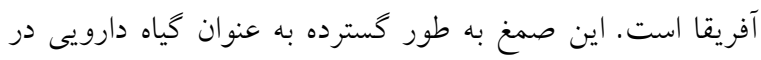

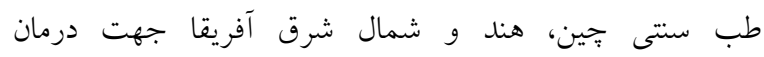

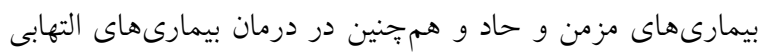
مانند التهاب روده بزرگ، روماتيسم مفصلى، ديابت استفاده

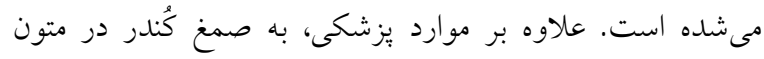

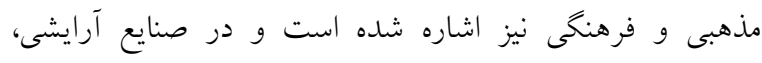

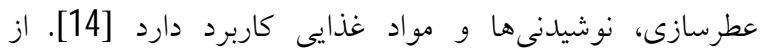

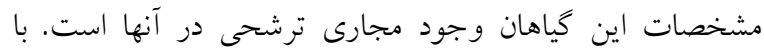
شكافى كه در تنه درختجه مولد كندر ايجاد مى كند شيرابه سفيد رنكى كه همان صمغ رزينى كندر است خارج مى شودد. اين شيرابه در مجاورت هوا به تدريج سفت شده و به صورت قطعات كو:جى بدون شكل يا كروى به رنخ سفيد، زرد روشن، زرد مايل

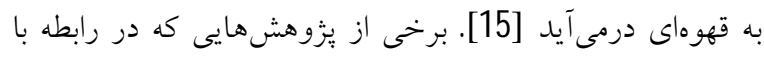

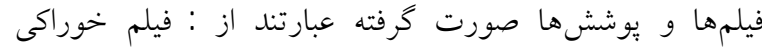

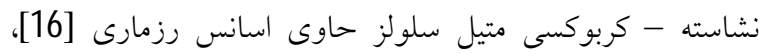

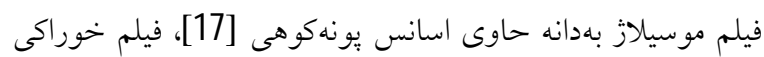

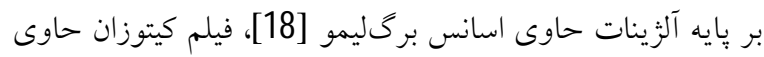

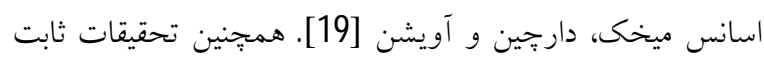

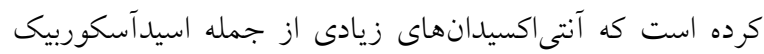

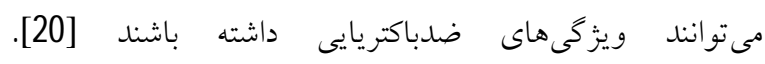
Zambuchini

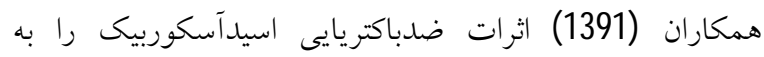

1. Frankincense

2. Gum olibanum

3. Boswellia

4. Sapindales
كوشت شترمرغ نسبت به كوشت دامهاى ديخر داراى مزيتهاى

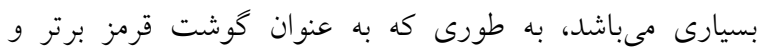

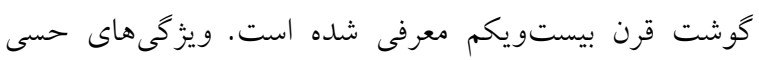

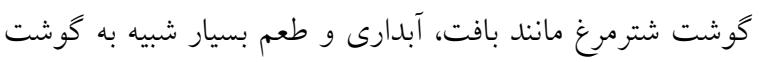

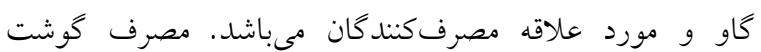

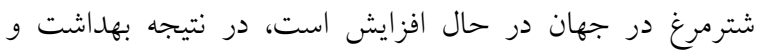

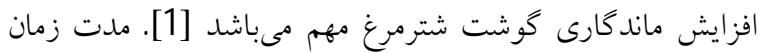

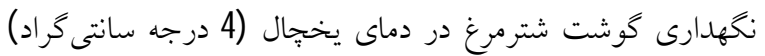

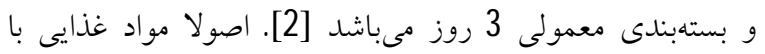
منشا حيوانى به عنوان يك منبع تغذيهاى بسيار مهم به علت دارا بودن بروتئين بالا و اسيدهاىآمينه ضرورى در رزيم غذايى انسان محسوب مىشوند. با اين حال اين منابع به دليل حساسيت بالا در برد

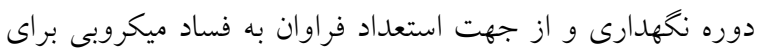

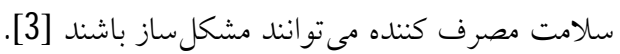
سرد كردن، انجماد، بستهبندى اتمسفر اصلاحشده و تيمارهاى

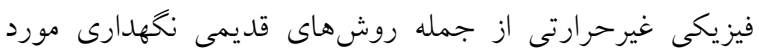

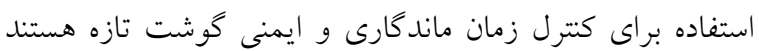

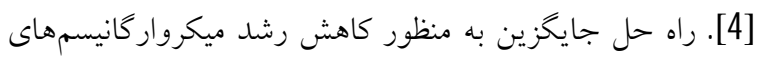

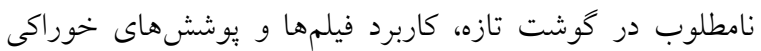

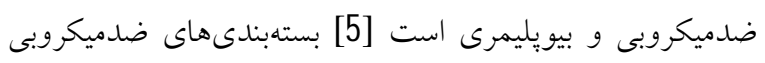

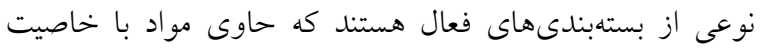

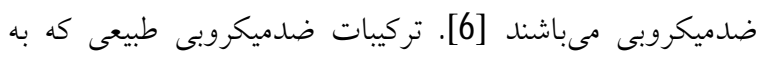

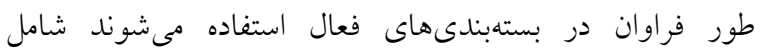

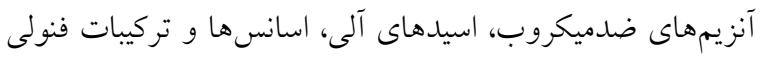

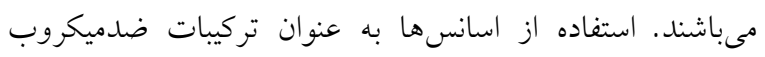

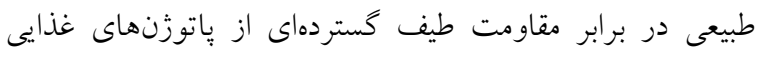

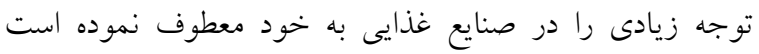

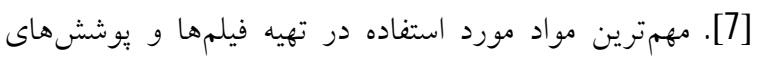

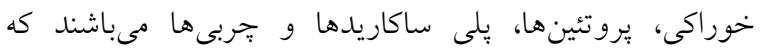

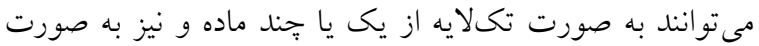
جندلايه تهيه شوند [8]. به طور كلى فيلمهاى خوراكى در مقايسه با فيلمهاى مصنوعى از ويزگىهاى مكانيكى و فيزيكى مناسبى برخوردار نيستند و به تنهايى براى بستهبندى مواد غذايى مطلوب 
قرار داده شدند[23].

\section{2-222 - تعيين تركيبات شيميايى گوشت شترمرغ}

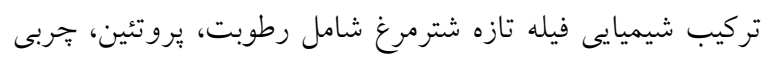
و خاكستر كل به روش ( AOAC Int., Arlington, VA. (AOAC) اندازهگيرى شد [24).

\section{3-2-2 - آماده سازى محلول فيلمها}

توليد فيلم دولايه زلاتين/صمغ كندر (G/F) با اندكى تغيير به

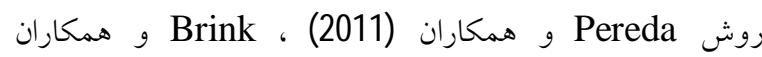
(2019)، وجدان و همكاران (1394) تهيه شد. فيلم دولايه

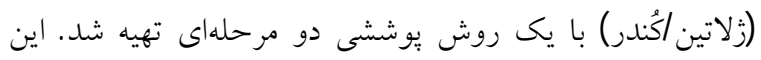
روش شامل تشكيل يك فيلم و يس از خشك شدن آن، محلول

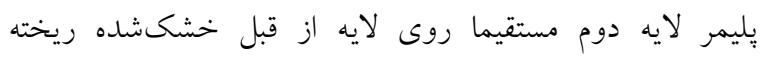

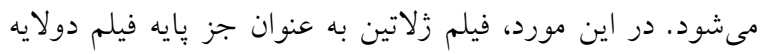
استفاده كرديد و محلول فيلم كُندر روى آن ريخته شد. ابتدا 3

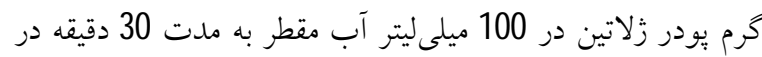

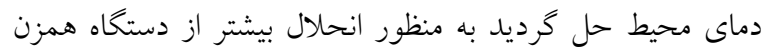

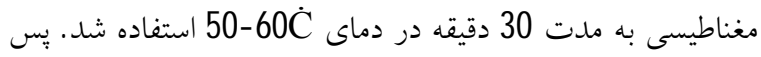

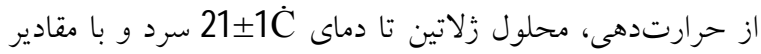

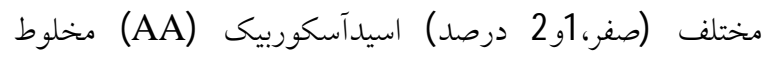

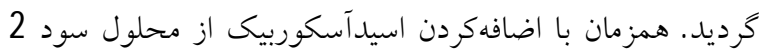

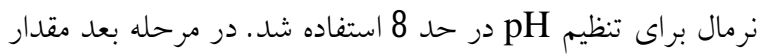

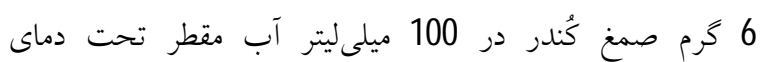

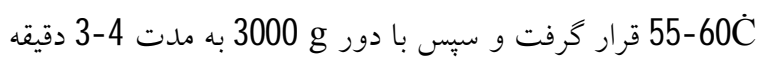

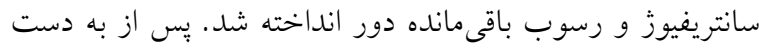

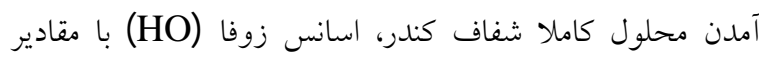

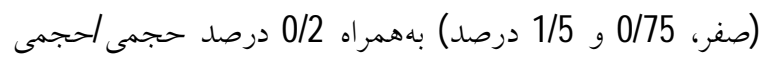

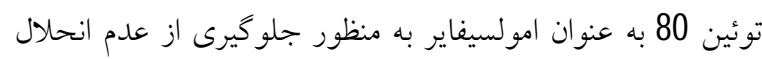
اسانس زوفا (HO) اضافه شد. لازم به ذكر است كه از حليسرول

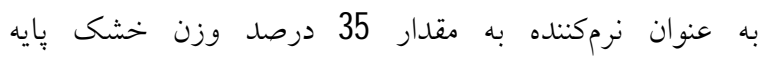

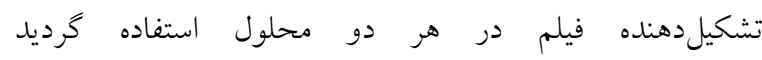

.[26, 25 ، 11]

422 - ارزيابى فعاليت ضدباكتريايى فيلم

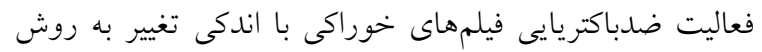

تنهايى و در تركيب با برخى اسيدهاى آلى بررسى كردهاند

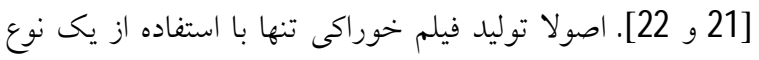
بليمر، ويزگىهاى مطلوبى را در برخى زمينها از خود نشان

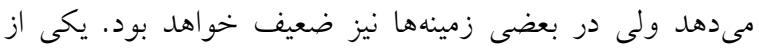
راههاى بهبود ويزكى هاى فيلم خوراكى، تركيب بيويليمرها و توليد بيوفيلمهاى مركب است. هدف از اين يزوهش توليد و

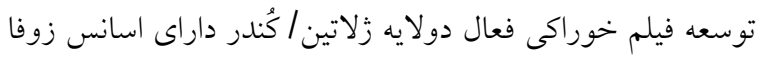

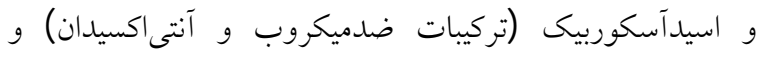
بررسى فعاليت ضدميكروبى آن بر روى سويههاى عامل فساد

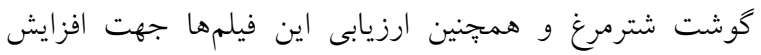

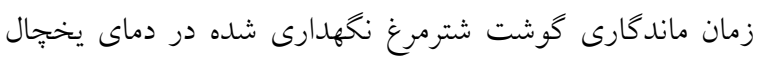

$$
\text { (4 درجه سانتى گراد) مى باشداند. }
$$

\section{2- مواد و روش ها}

- 2

كوشت تازه شترمرغ (Struthiocamelus) از كشتاركاه مشهد

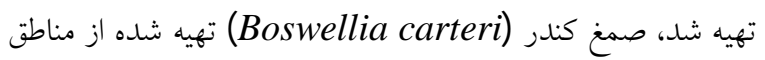
جنوبى استان كرمان كه در مركز هرباريوم و كياه شناسى دانشخاه

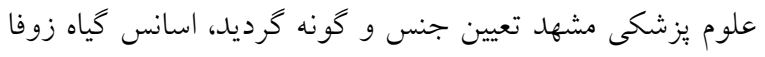
(شركت باريج اسانس، كاشان، (Hyssopus officinalis L,)

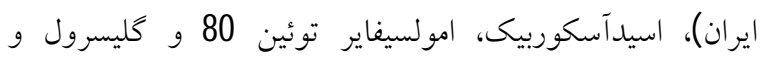

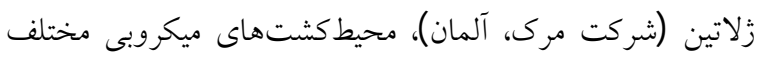

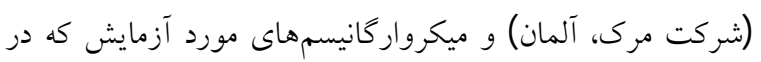

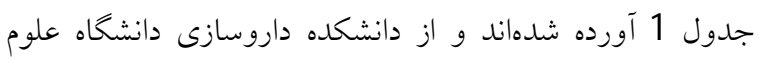
يزشكى مشهد تهيه كرديدند.

22 2 2-222 - 1آمادهسازى نمونه گوشت شترمرغ نمونههاى فيله شترمرغ به تاريخ كشتار روز (شهريورماه 1397)

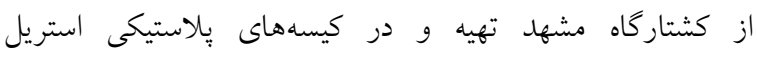

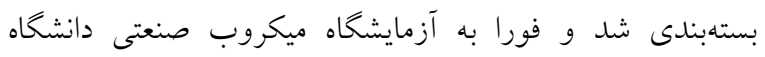

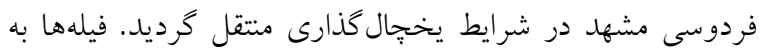

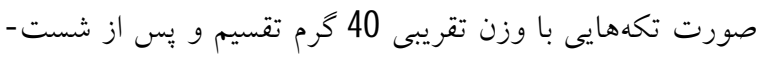
وشو با آب فراوان، جهت آبكشى بر روى صافى هاى يلاستيكى 
ابتدا گوشت تازه شترمرغ در شرايط استريل به نمونههاى با وزن

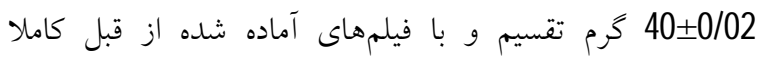

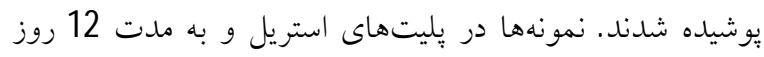

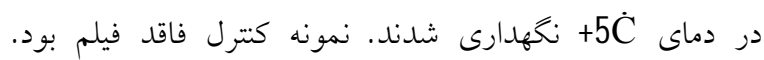

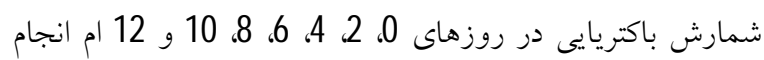

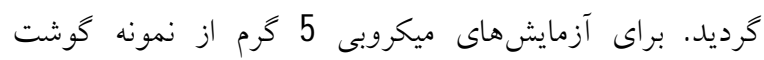

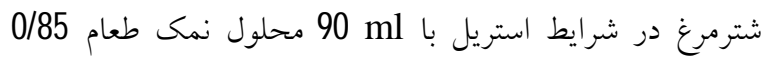
درصد مخلوط و هموزن شد. سبس رقتهاى موردنياز تهيه

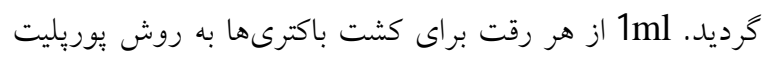

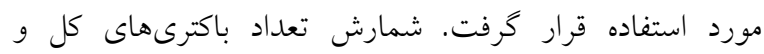

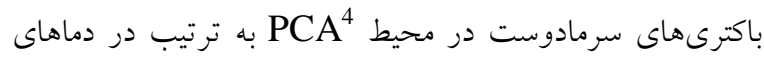
37C

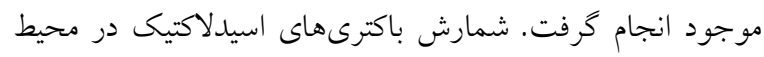
بى هوازى در محيطكشت MRS-agar در دماى 30 به به مدات 2 تا3 روز و به روش يوريليت انجام شد [22 ، 20 29 و 30].

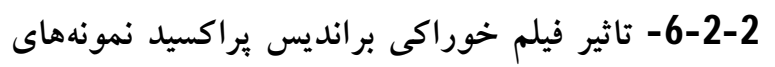
كوشت

تعيين ميزان يراكسيد نمونههاى كوشت شترمرغ مطابق با روش

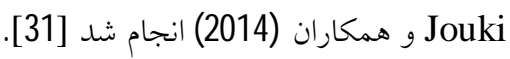

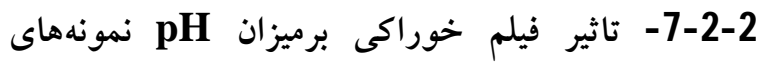
كوشت Sallam نمونهاى كوشت شترمرغ طيق روش pH اندازهيرى

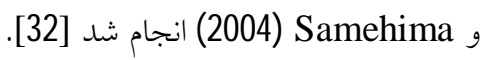
822 2 version 24 آناليز واريانس نتايج نيز با استفاده از نرم افزئ

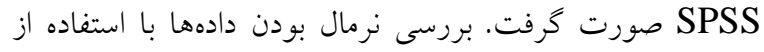

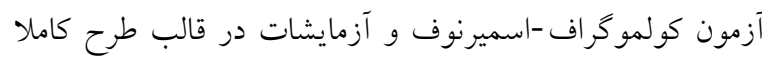
تصادفى با آرايش فاكتوريل و در سه تكرار انجام شدنداف. مقايسه ميانكين توسط آزمون دانكن و در سطح اطمينان 95 درصد انجام

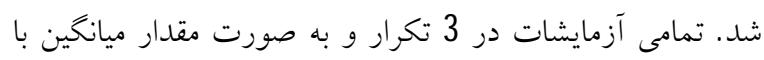
انحراف استاندارد كزارش شدند.

4. Plate Count Agar
انتشار ديسك در آكار11 بررسى شد [27]. سويههاى باكتريايى و

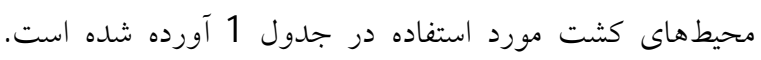
براى فعالسازى باكترىها، ابتدا سوسبانسيون ميكروبى به صورت التهات

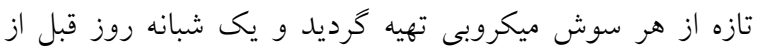

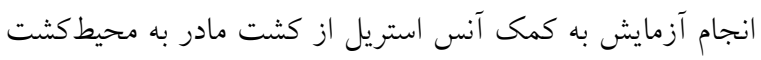
شيبدار Muller Hinton Agar براى باكترى تلقيح انجام شد.

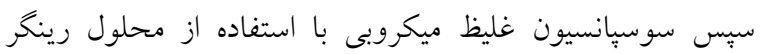

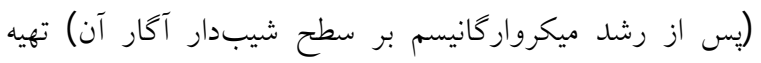

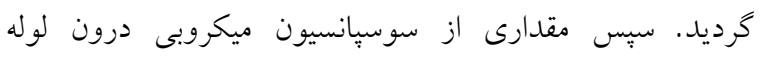

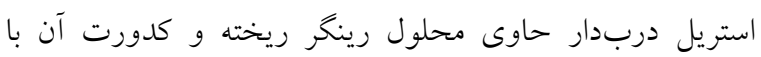

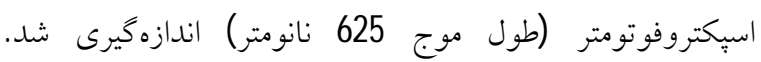
رقتسازى محلول سوسيانسيون تا زمان برابرشدن كدورت محلول Q5 مكفارلند و سوسبانسيون ميكروبى ادامه يافت [28].

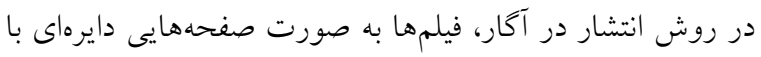

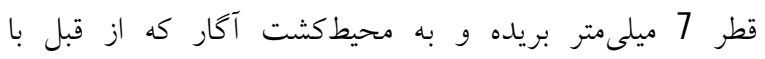
10 - $10^{6}$ CFU/ml

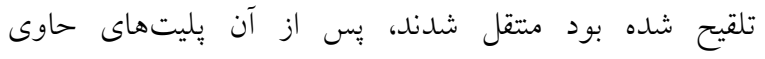
محيط كشت آلوده همراه با فيلمهاى ضدميكروبى به مدت بند 24

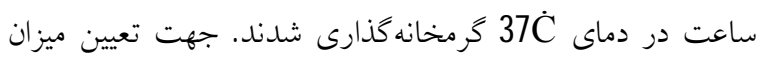
ممانعتكنندكى فيلم خوراكى از رشد باكترىها، قطر هاله هاى

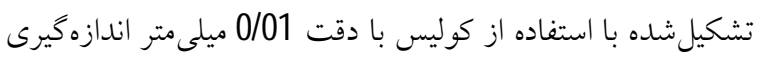
شد [27].

Table 1 microorganisms and culture medium of test

\begin{tabular}{ccc}
\hline $\begin{array}{c}\text { Culture } \\
\text { medium }\end{array}$ & Strains & Microorganisms \\
\hline MHA $^{2} / \mathrm{BHA}^{3}$ & ATCC & $\begin{array}{c}\text { Psudomonas } \\
\text { aeroginosa }\end{array}$ \\
MHA/BHA & ATCC 6538 & Staphylococus aureus \\
& E.coli & Escherichia coli \\
MHA/BHA & O157:H7 & Bacillus cereus \\
MHA/BHA & ATCC11778
\end{tabular}

1. Agar Diffusion Method

2. Muller Hinton Agar

3. Brain Heart Infusion Agar 


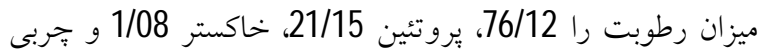

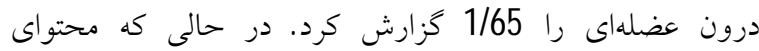

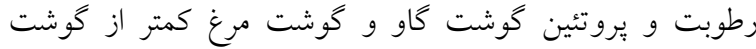

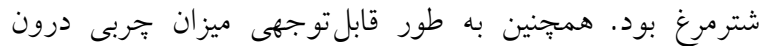

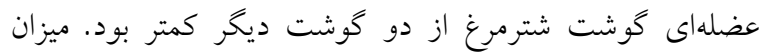

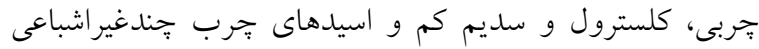

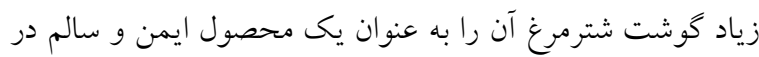

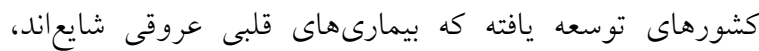
تبديل كرده است [33]. 3- نتايج و بحث 3-3 - نتايج درصد رطوبت، خاكستر، بروتئين و جربى گوشت شترمرغ

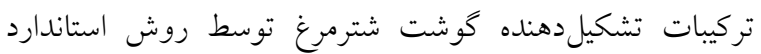

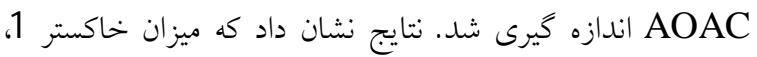

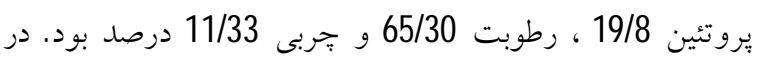

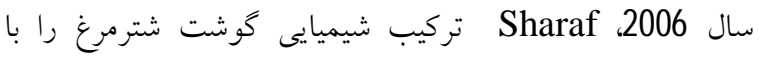
كوشت كاو و مرغ مقايسه كرد (جدول 2). نتايج آناليزهاى او كاو

Table 2 Chemical parameters of ostrich meat compared with beef and poultry (Sharaf, 2006)

\begin{tabular}{cccc}
\hline Poultry & Beef & Ostrich & Components \\
\hline 74.03 & 72.90 & 76.12 & Humidity \\
20.29 & 21 & 21.15 & Protein \\
4.70 & 5.07 & 1.65 & Intramuscular Fat \\
0.98 & 1.03 & 1.08 & Ash \\
\hline
\end{tabular}

شد. كه اين امر به خصوص در مورد نمونه فيلم حاوى 1/1/5\%

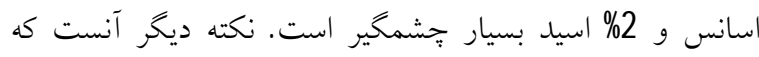

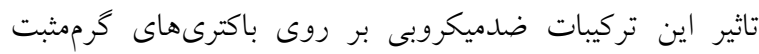

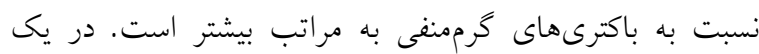

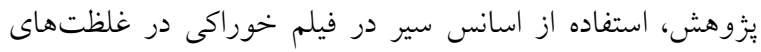

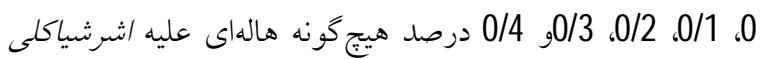

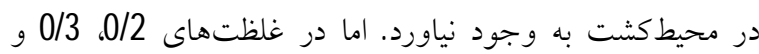

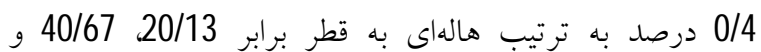

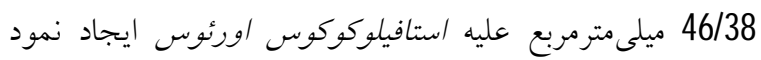

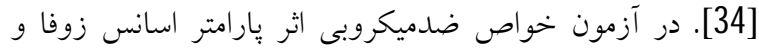

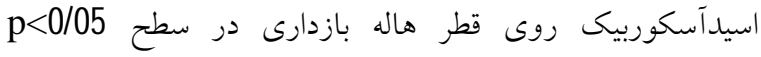

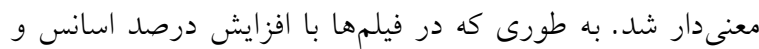
اسيد به صورت خطى رشد M.O ها مهار شدا. به عنوان مثال در تيمار داراى 2\% اسيد و 1/21/ اسانس، قطر هاله

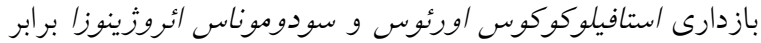

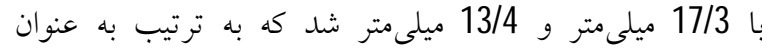

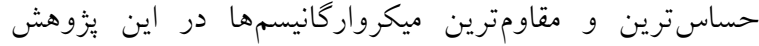

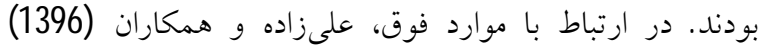

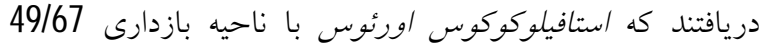
ميلىمترمبع حساسترين و سالمونلا تيفى موريوم با ناحيه

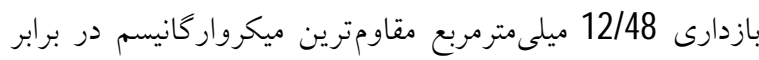
فيلم كيتوزان حاوى 2\% اسانس بنه بودند [35].

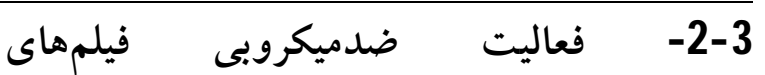
زلاتين -صمغ كُندر روى ميكرواركانيسمهاى

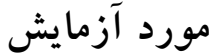

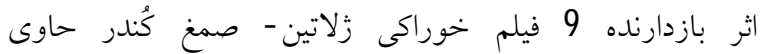

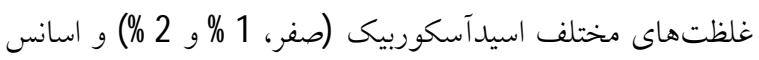

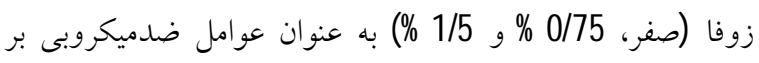

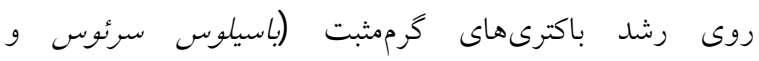

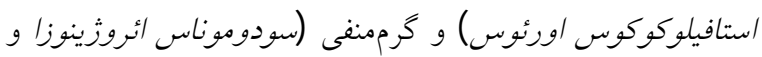

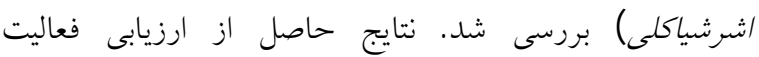

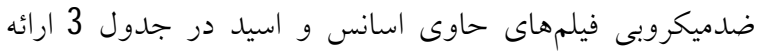

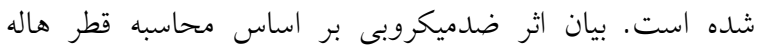

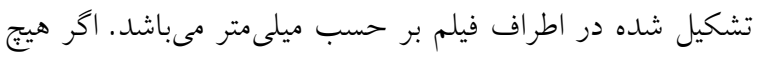

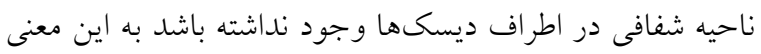

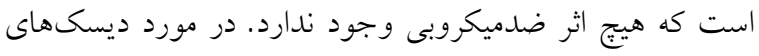

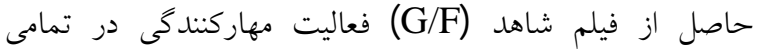
l M.O

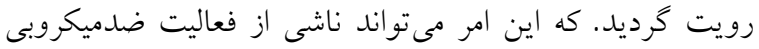

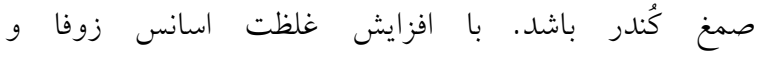

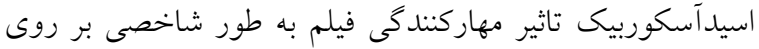

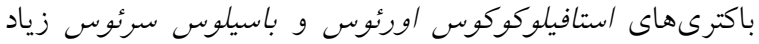


Table 3 Diameter of inhibition zone created by G/F bilayer film containing different concentrations HO and AA using Disk Diffusion Test

\begin{tabular}{cccccc}
\hline $\begin{array}{c}\text { Concentration AA } \\
(\% \mathrm{v} / \mathrm{v})\end{array}$ & $\begin{array}{c}\text { Concentration } \\
\text { HO }(\% \mathrm{v} / \mathrm{v})\end{array}$ & D.cereus & S.aureus & E.coli & P.aeroginosa \\
\hline \multirow{2}{*}{0} & 0 & $10.2 \pm 0.2^{\mathrm{a}}$ & $11.3 \pm 0.3^{\mathrm{a}}$ & $9.8 \pm 0.51^{\mathrm{a}}$ & $8.4 \pm 0.35^{\mathrm{a}}$ \\
& 0.75 & $11.5 \pm 0.1^{\mathrm{b}}$ & $13.8 \pm 0.3^{\mathrm{b}}$ & $10.7 \pm 0.2^{\mathrm{b}}$ & $10.1 \pm 0.4^{\mathrm{b}}$ \\
& 1.5 & $13 \pm 0.71^{\mathrm{c}}$ & $15.2 \pm 0.5^{\mathrm{c}}$ & $11.5 \pm 0.8^{\mathrm{c}}$ & $11.1 \pm 0.2^{\mathrm{c}}$ \\
\hline \multirow{2}{*}{1} & 0 & $12.1 \pm 0.4^{\mathrm{b}}$ & $13.2 \pm 0.3^{\mathrm{b}}$ & $10.2 \pm 0.8^{\mathrm{b}}$ & $10 \pm 0.25^{\mathrm{b}}$ \\
& 0.75 & $13.8 \pm 0.2^{\mathrm{c}}$ & $14.6 \pm 0.2^{\mathrm{d}}$ & $11.5 \pm 0.3^{\mathrm{c}}$ & $11.2 \pm 0.7^{\mathrm{c}}$ \\
& 1.5 & $15.5 \pm 0.3^{\mathrm{d}}$ & $16.3 \pm 0.5^{\mathrm{e}}$ & $13.1 \pm 0.7^{\mathrm{d}}$ & $12.6 \pm 0.2^{\mathrm{d}}$ \\
\hline \multirow{2}{*}{2} & 0 & $13.5 \pm 0.2^{\mathrm{c}}$ & $14 \pm 0.25^{\mathrm{d}}$ & $11.3 \pm 0.3^{\mathrm{c}}$ & $10.8 \pm 0.5^{\mathrm{bc}}$ \\
& 0.75 & $14.4 \pm 0.2^{\mathrm{e}}$ & $15.8 \pm 0.6^{\mathrm{c}}$ & $12.8 \pm 0.1^{\mathrm{d}}$ & $12 \pm 0.6^{\mathrm{dc}}$ \\
& 1.5 & $16.7 \pm 0.3^{\mathrm{f}}$ & $17.3 \pm 0.1^{\mathrm{f}}$ & $14.3 \pm 0.5^{\mathrm{e}}$ & $13.4 \pm 0.1^{\mathrm{e}}$ \\
\hline
\end{tabular}

Reported values correspond to the mean \pm standard deviation. Different letters in the same column indicate significant differences $(\mathrm{P}<0.05)$.

AA: Acid Ascorbic, HO: Hyssopus officinalis essential Oil

تغييرات ميزان بار باكتريايى كل (Total Viable Count) در

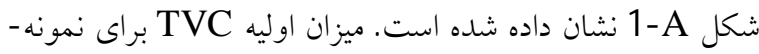

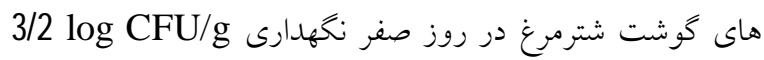

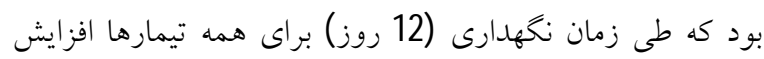

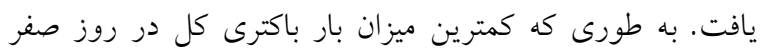

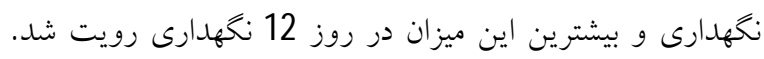

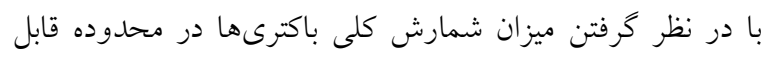

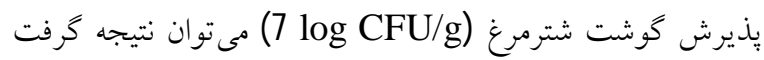

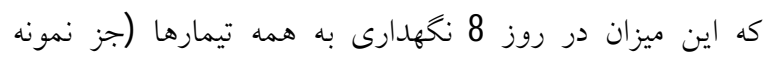

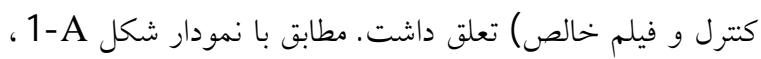

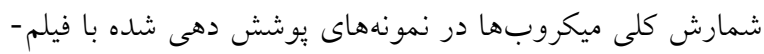

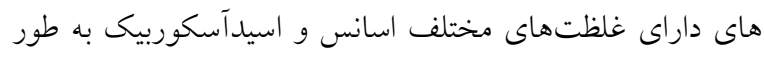

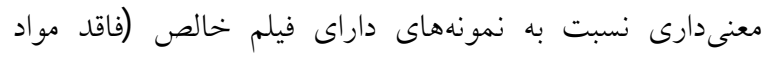

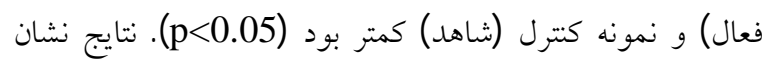

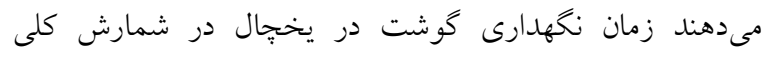

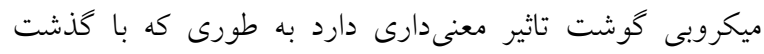

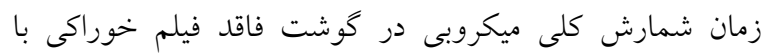

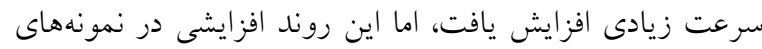
يوشش دهى شده با فيلم و به ويزٔه فيلمهاى حاوى اسانس به

$$
\text { طور معنى دارى كمتر بود (شكل A A 11). }
$$
ذكر اين نكته ضروريست كه با بيشتر شدن غلظت مواد نخهدارنده

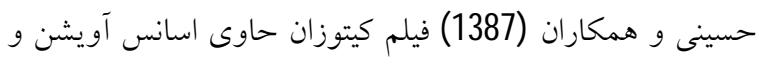

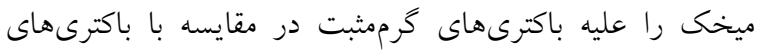

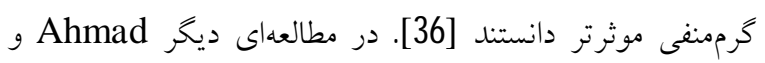

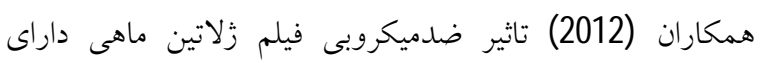

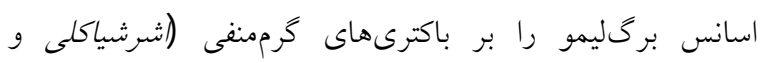

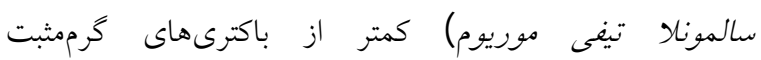

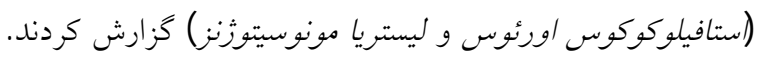
دليل اين امر حضور غشاى خارجى اضافى در باكترىهاى كرممنفى اعلام شده است [37]. خاصيت ضدميكروبى فيلمهاى

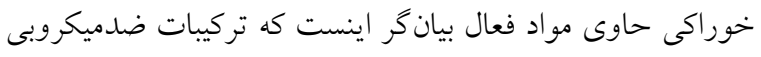

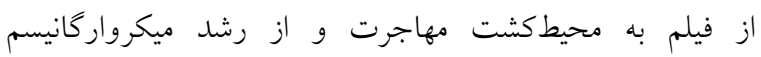

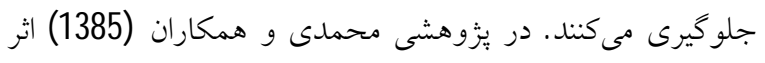

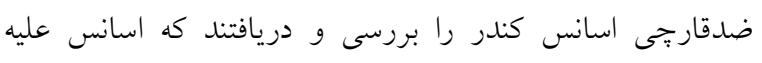

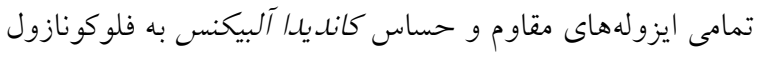

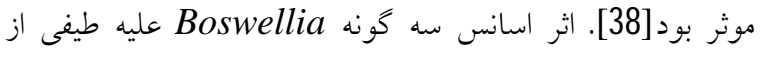

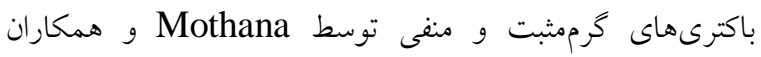

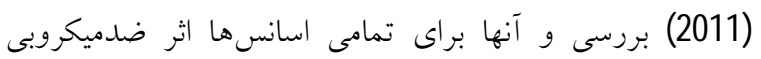

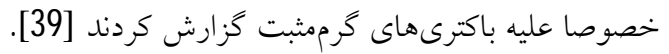
3 - فعاليت ضدميكروبى فيلم خوراكى دولايه بر كيفيت ميكروبى گوشت شترمرغ 

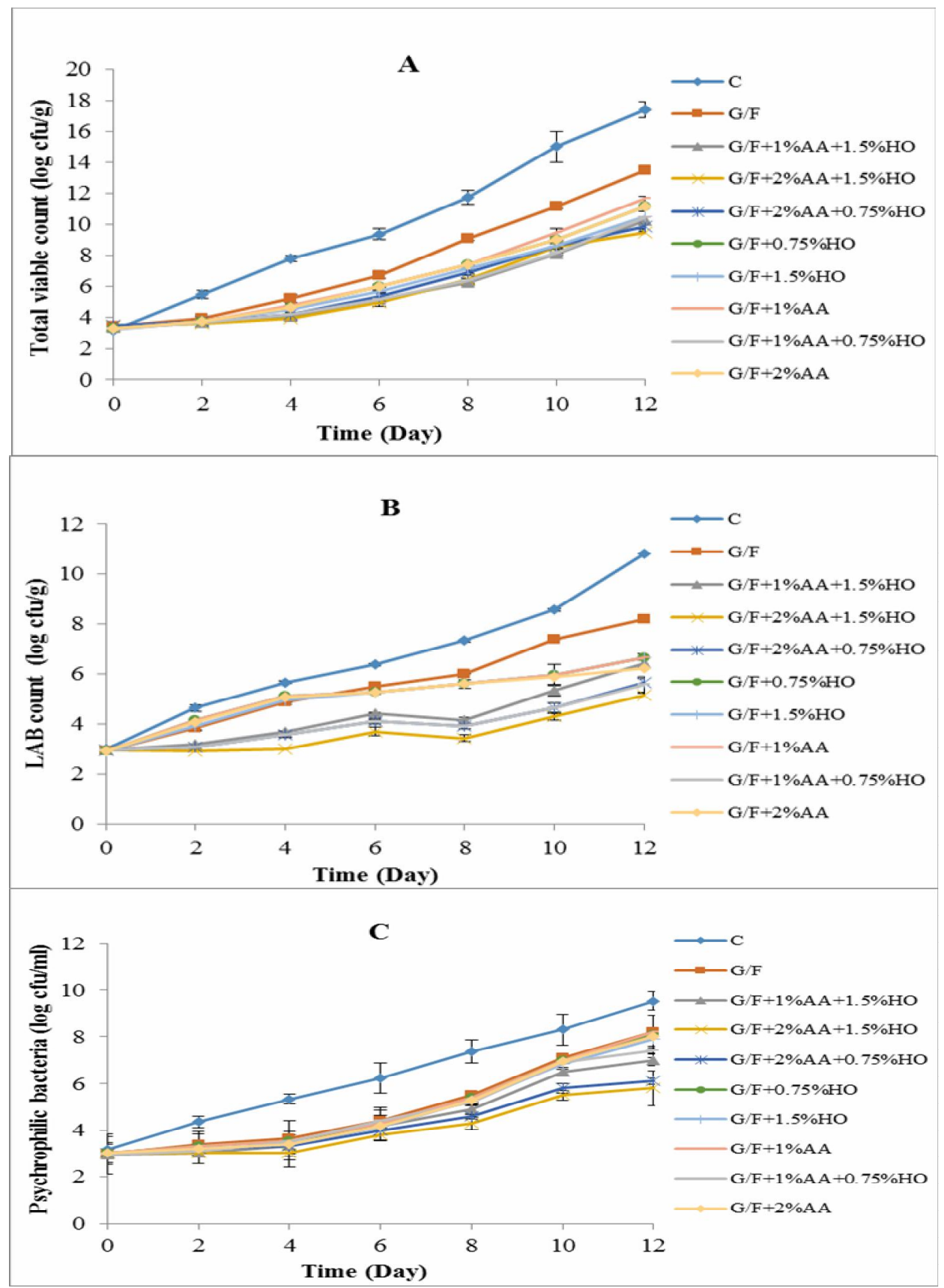

Fig 1 Microbial changes of ostrich fillets with various treatments during the storage at refrigerator C: control sample (without film), G/F: pure film

باكترىهاى اسيدلاكتيك در pH هاى نسبتا بايين و مقاومتر بودن

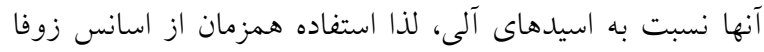

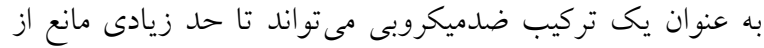
رشد افزايشى اين باكترىها كردد.

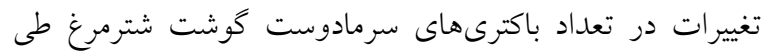

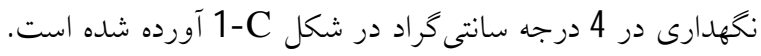

مقادير مربوط به تغيير جمعيت باكترىهاى اسيدلاكتيك كوشت شترمغ در شكل B B نشان داده شده است. تعداد اوليه باكترىهاى اسيدلاكتيك 2/95 log CFU/g بود. اين تعداد در التران

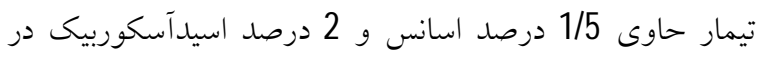

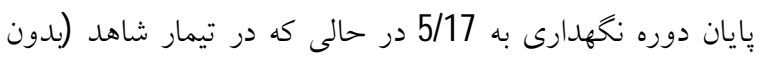

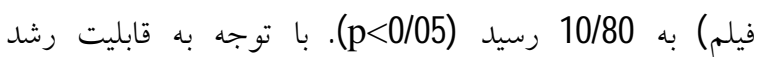


كرفت كه كنترل رشد باكترىهاى اسيدلاكتيك در نمودار شمارش LAB

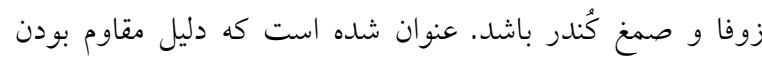

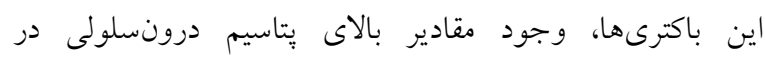

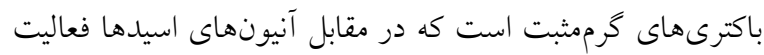

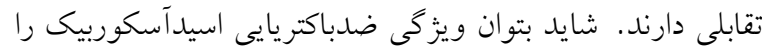

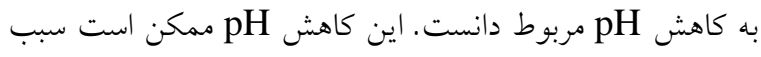

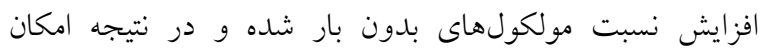

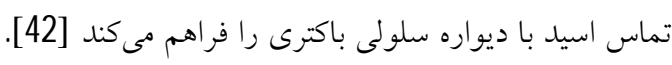

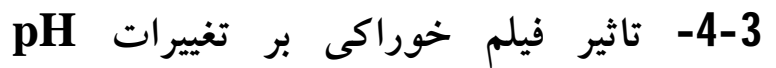

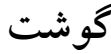

تغييرات مقدار pH نمونههاى كوشت شترمرغ نخهلارىشده در 5C غلظتهاى بالاى اسيد و اسانس (G/F+2\%AA+1.5\%HO و G/F+2\%AA+0.75\%HO) در روزهاى اوليه نخهدارى،

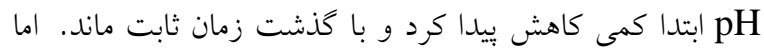

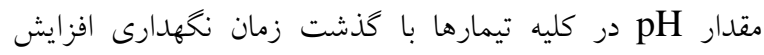
يافت كه اين افزايش در مورد نمونه كنترل با سرعت بيشترى

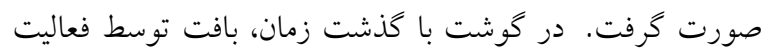

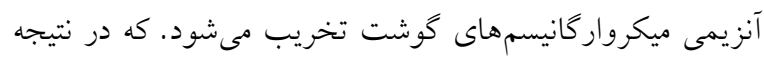

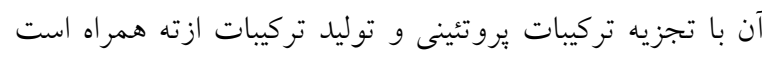

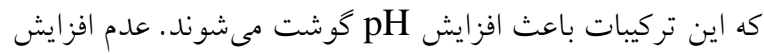

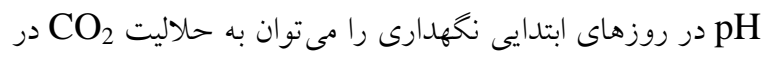

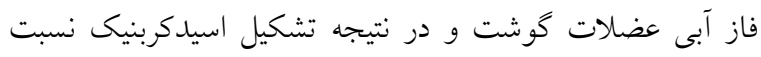
داد. هم جنين افزايش

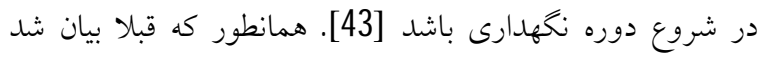

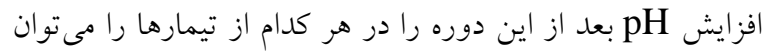

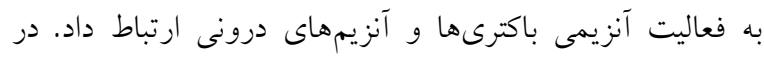

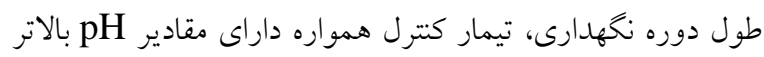

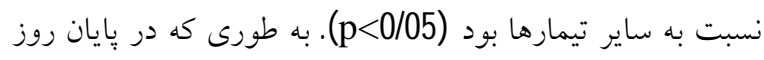

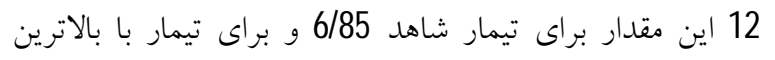

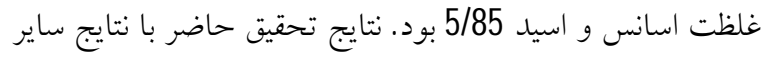

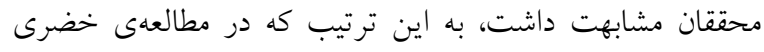
احمدآباد و همكاران (1391) و Lu و همكاران (2009) نيز ابتدا

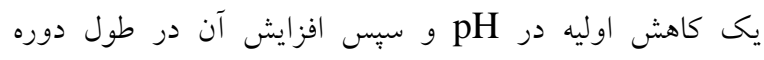

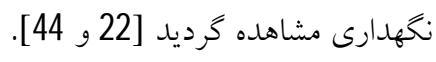

مقدار شمارش كلى سرمادوستها در طول زمان تغيير كرده است (p<0/05) نحهارى تقريبا معادل

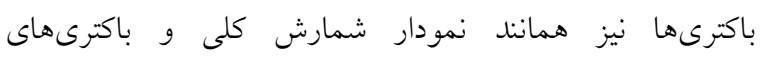

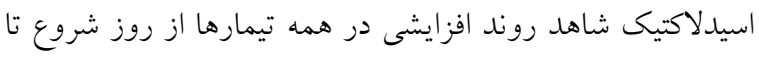
بايان نخهدارى هستيم. با اين تفاوت كه روند افزايشى تعداد

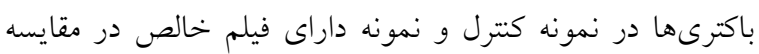

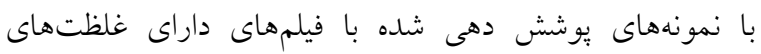

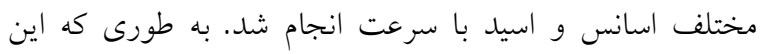
تعلداد در بايان دوره نخهارى (روز و 8/20log CFU/g به ترتيب براى تيمارهاى كتترل و فيلم فاقد

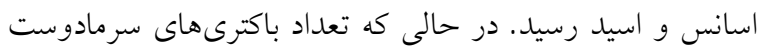

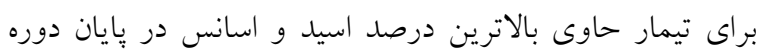
نخهارى

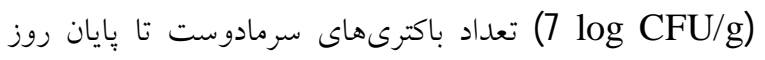

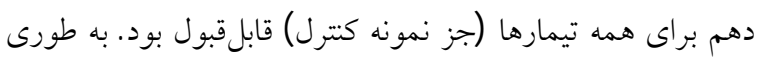

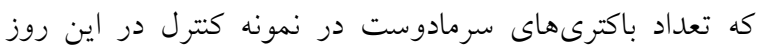

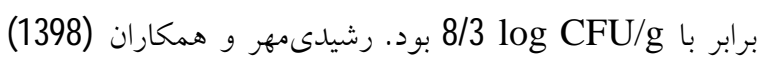

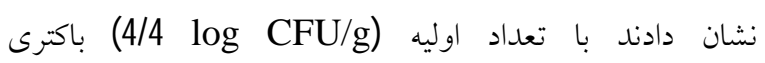

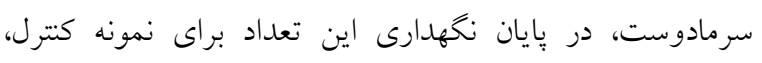

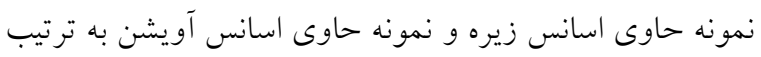

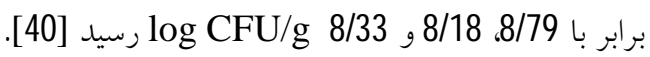

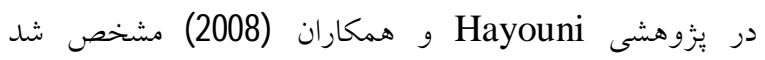
تركيبات ترينى حاوى كروههاى فنلى اسانس مريم كلى در شر شرايط

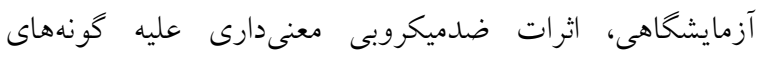

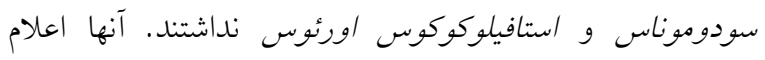

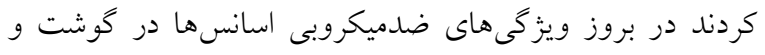

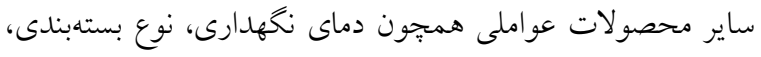

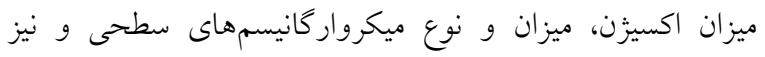

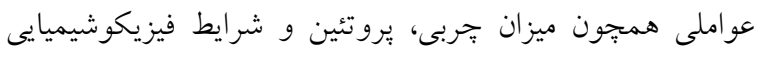

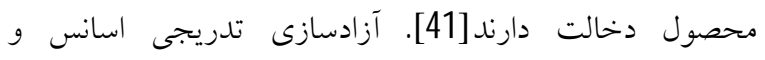

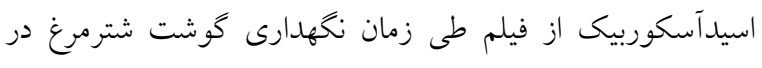
يخجال عامل اثربخشى ضدميكروبى فيلم حاوى مواد فعال در

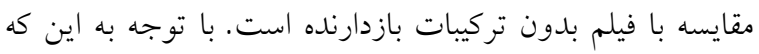

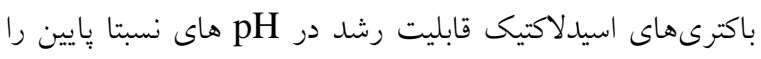

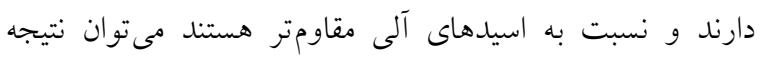




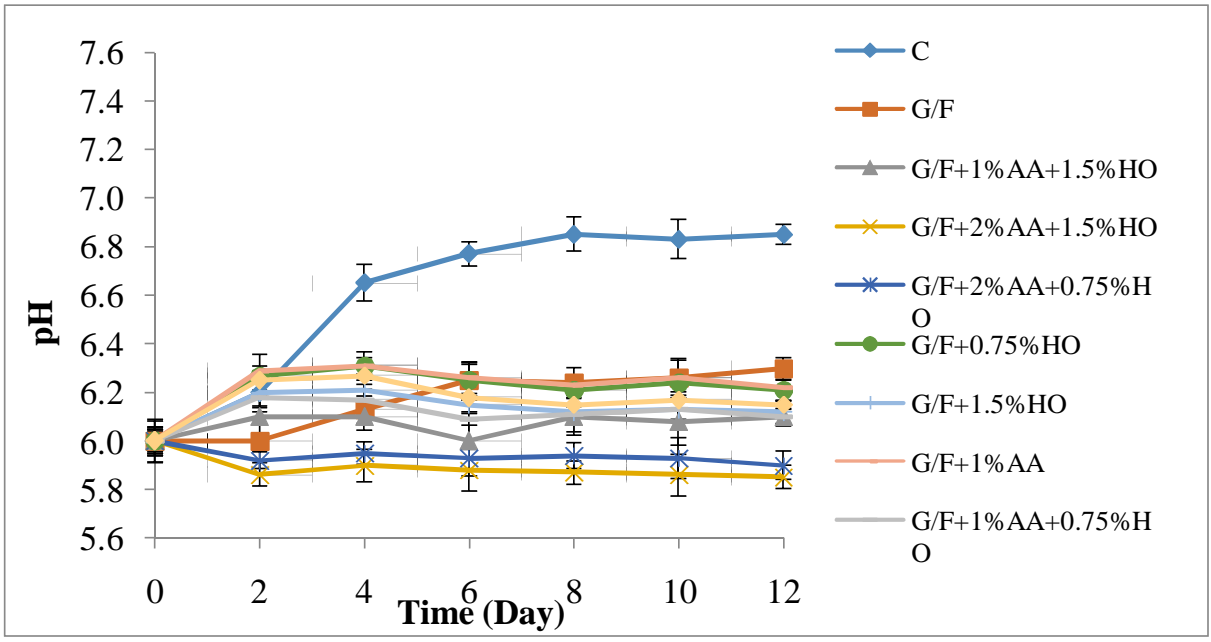

Fig $2 \mathrm{pH}$ changes of ostrich fillets during storage at refrigerator

فاصله زمانى 8 تا 10 روز مقدار اندكى كاهش يافت. شايد علت

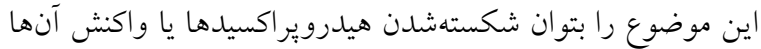
با يروتئينهاى موجود در سطح گوشت نسبت داد كه با يافتهاى

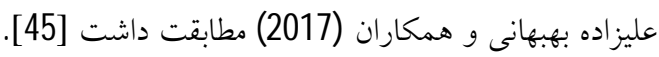
داشتن خاصيت آنتىاكسيدانى اسيدآسكوربيك و وجود تركيبات فنولى و آنتىاكسيدانى موثر در اسانس زوفا و صمغ كندر عوامل موثرى در جلو گيرى از افزايش عدد براكسيد به شمار مىروند. به طورى كه با بيشتر شدن درصد اسانس و اسيد در فيلمهاى خوراكى، درصد تغيير عدد يراكسيد نمونهاى كوشت شترمرغ

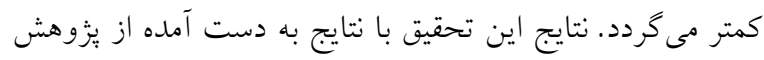
Jouki

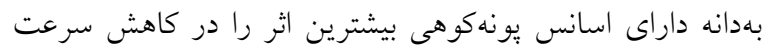

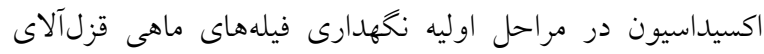
رنخين كمان دارد، همسو بود [17]. Ojagh و همكاران (2010)

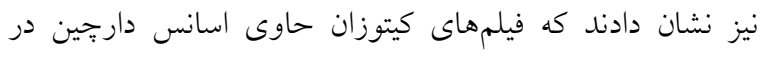

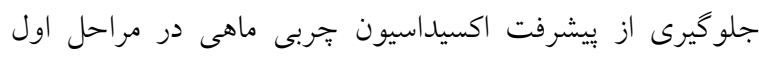

$$
\text { موثر بودند [46]. }
$$

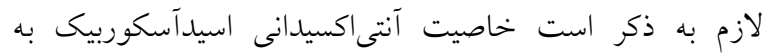

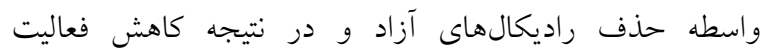

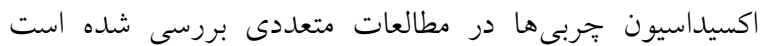

\section{3 -5 - تاثير فيلم خوراكى بر تغييرات عدد ير اكسيد كوشت شترمرغ}

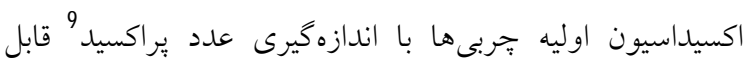

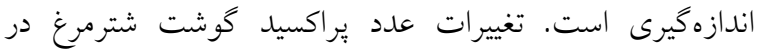
كروههاى بدون فيلم و يوششدهى شده با فيلم فاقد و حاوى

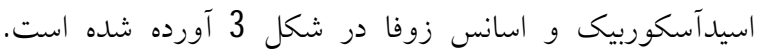

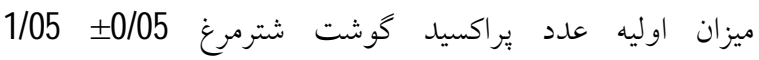

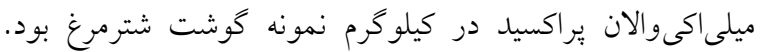
ميزان عدد يراكسيد در روز اول نخهارى در تمامى نمونههاى

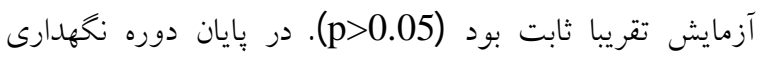

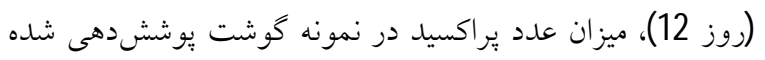

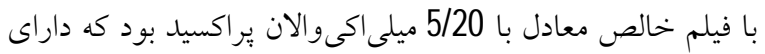

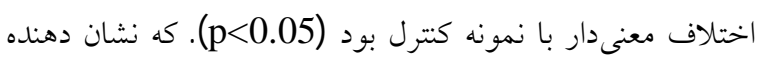

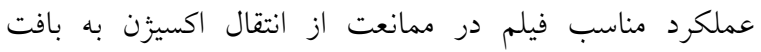

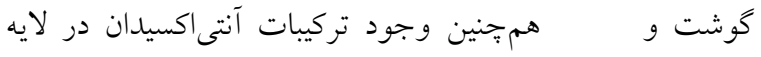
صمغ كُندر است كه از اكسيداسيون جلو گيرى مىنمايند. نتايج همجنين نشان داد اختلاف معنى دارى در مقدار علد يراكسيد كوشتهاى يوششدهى شده با فيلمهاى حاوى غلظتهاى نداى بالاتر

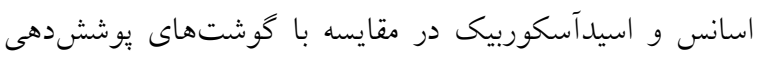

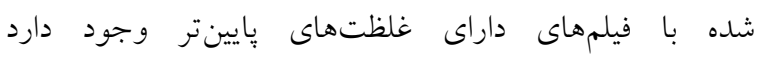
(p<0.05)

\footnotetext{
${ }^{9}$ Peroxide value
} 


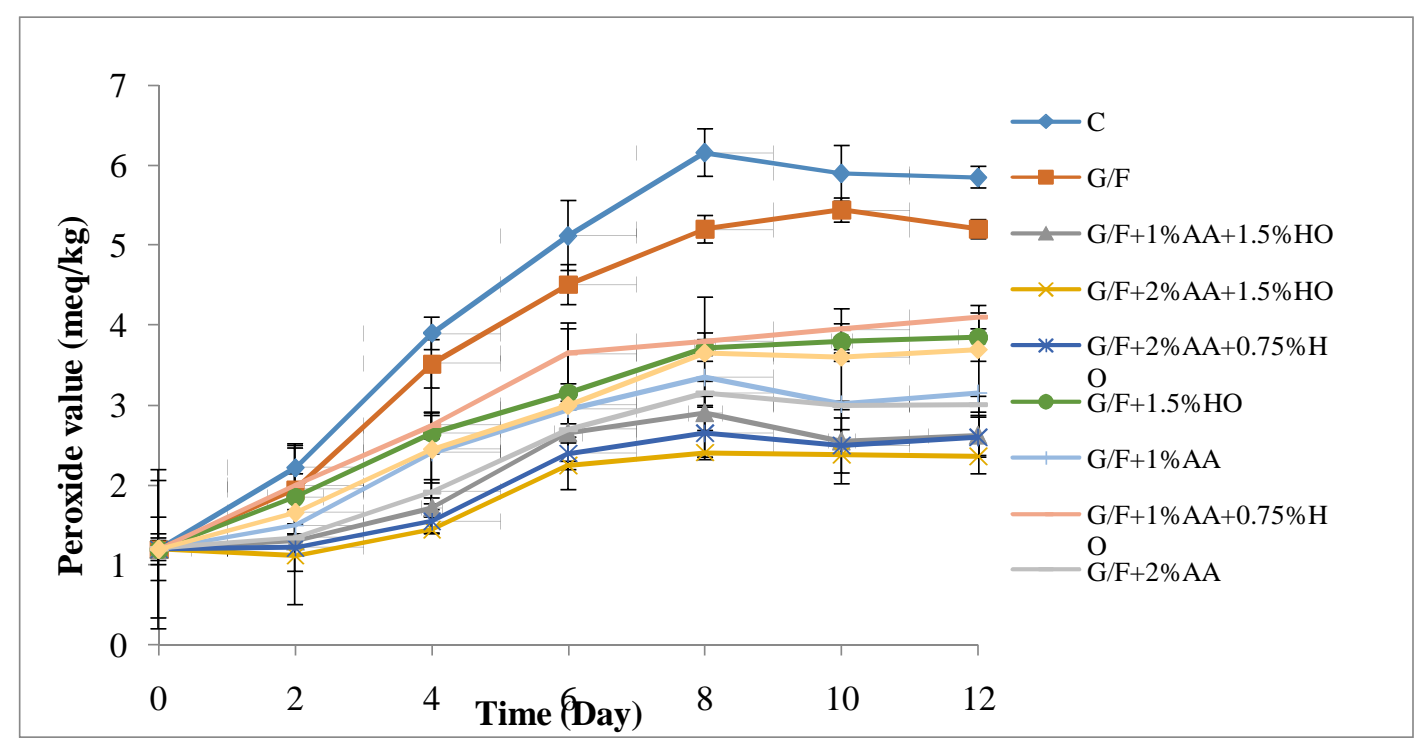

Fig 3 Peroxide value changes of ostrich fillets during storage at refrigerator

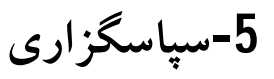

بدينوسيله از زحمات سركار خانم مهندس شهناز افشاريان و

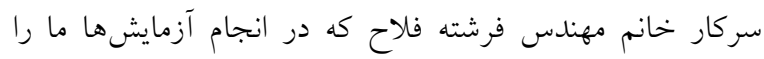

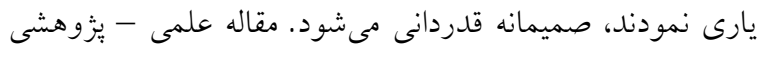

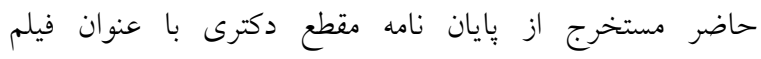

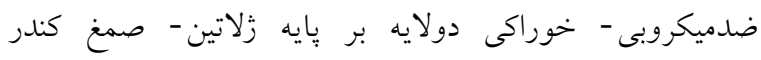
در تركيب با اسيدآسكوربيك و اسانس بـانس (Boswellia carteri) زوفا (Hyssopus officinalis L) جهت افزايش زمان ماندگارى فيله شترمرغ در دماى يخجال با كد 47102 در گروه مهندسى علوم و صنايع غذايى دانشكده كشاورزى دانشعاه فردوسى مشهد مىباشد. لذا نويسندگان مقاله بر خود لائ لازم

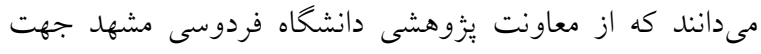
يارى رساندن در انجام طرح صميمانه سياسكزارى نمايند.

\section{6 - منابع}

[1] Seydim, A. C., Acton, J. C., Hall, M. A., and Dawson, P. L. (2006). Effects of packaging atmospheres on shelf lifequality of ground ostrich meat. Meat Science, 73(3),503-510

[2] Iran IoSaIRo. Fresh red meat-Specifications 2008. 1: [Available from: http:// www.isiri.org/portal /files/std/9717.pdf

[3] Bazargani-gilani B, Aliakbarlu J, Tajik H.

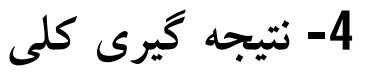

به طور كلى نتايج اندازهيرى بار ميكروبى كل، سرمادوست و

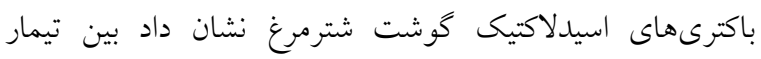

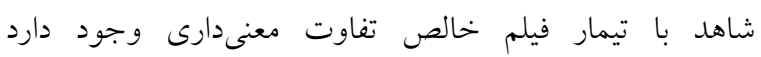
(p<0/05)

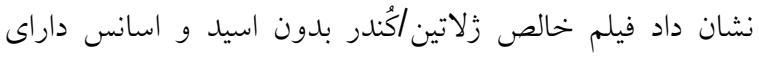

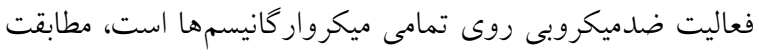
دارد. تحقيق حاضر نشان داد كه استفاده از فيلم دولايه

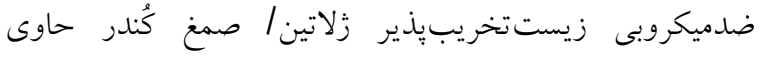

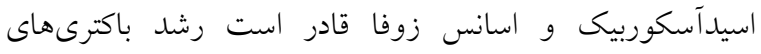

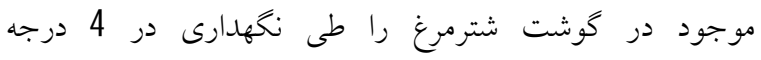

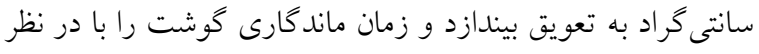

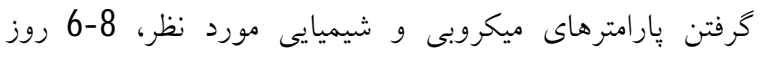
افزايش دهد. در مجموع مىتوان كفت فيلم ضدميكروبى حاوى مانى

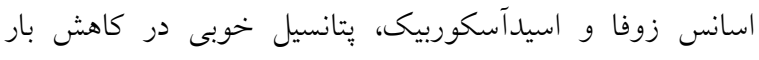

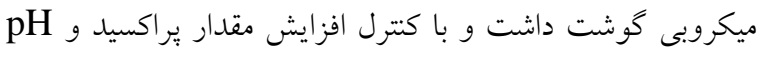

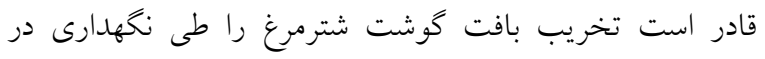
يخجال به تعويق بيندازد. 
osteoarthritis with a herbomineral formulation: a double- blind ,placebo-controlled, crossover study. J Ethnopharmacol. 33: 91 - 9.

[14] Hosain, N.A., Ghosh, R., Bryant, D.L., Arivett, B.A., Farone, A.L. and Kline, P.C., 2019. Isolation, structure elucidation, and immunostimulatory activity of polysaccharide fractions from Boswellia carterii frankincense resin. International journal of biological macromolecules, 133, pp.76-85.

[15] Ghasemidehkordi N. 2002. Iranian herbal pharmacopoeia. First edition. Ministry of health and medical education Tehran. Pp: 64754

[16] Mohsenabadi, N., Rajaei, A., Tabatabaei, M. and Mohsenifar, A., 2018. Physical and antimicrobial properties of starch-carboxy methyl cellulose film containing rosemary essential oils encapsulated in chitosan nanogel. International journal of biological macromolecules, 112, pp.148-155.

[17] Jouki, M., Yazdi, F.T., Mortazavi, S.A. and Koocheki, A., 2014. Quince seed mucilage films incorporated with oregano essential oil: Physical, thermal, barrier, antioxidant and antibacterial properties. Food Hydrocolloids, 36, pp.9-19.

[18] Natalia, R., Herrera, M.L., Matiacevich, S. 2017. Active films based on alginate containing lemongrass essential oil encapsulated: effect of process and storage conditions. Journal of food and Bioproducts Processing, Accepted Manuscript.

[19] Hosseini MH, Razavi SH, Mousavi MA. Antimicrobial, physical and mechanical properties of chitosan-based films incorporated with thyme, clove and cinnamon essential oils. J Food Process and Preserv 2009; 33: 727-43.

[20] Tajkarimi MM, Ibrahim SA, Cliver DO. 2010. Antimicrobial herb and spice compounds in food. Food Control, 21(9): 1199-218.

[21] Zambuchini, B, Fiorini D, Verdenelli MC, Orpianesi C, Ballini R. 2008. Inhibition of microbiological activity during sole (Solea solea L.) chilled storage by applying ellagic and ascorbic acids. LWT - Food Science and
2015. Effect of pomegranate juice dipping and chitosan coating enriched with Zataria multiflora Boiss essential oil on the shelf life of chicken meat during refrigerated storage. Innov Food Sci Emerg Technol . 29:280-7

[4] Davidson, P. M. Chemical preservatives and naturally antimicrobial compounds, in: L.R. Beuchat, T.J. Montville, M.P Doyle (Eds.), Food Microbiology: Fundamentals and Frontiers, ASM Press, Washington DC, 2001, pp. $593-628$

[5] Lacroix, M., Cooksey, M. Edible films and coatings from animal origin proteins, in: J.H. Han (Eds.), Innovations in Food Packaging, Academic Press, London, 2005, pp. 301-317.

[6] Appendini, P. and Hotchkiss, J. H. (2002). Review of antimicrobial food packaging. Innov. Food Sci. Emerg. 3, 113-126.

[7] Burt, S., 2004, Essential oils: their antibacterial properties and potential applications in foods- a review, International Journal of food microbiology, 94(3), 223-253.

[8] Rivero, S., Garcia, M.A., Pinotti, A. 2009. Composite and bi-layer films based on gelatin and chitosan. Food engineering, 90(4):531-539

[9] Gómez-Guillen, M. C., M. Pérez-Mateos, J. Gómez-Estaca, E. López-Caballero, B. Giménez, and P. Montero. 2009. Fish gelatin: a renewable material for developing active biodegradable films. Trends in Food Science and Technology, 20: 3-16.

[10]. Azeredo, H. 2009. Nanocomposites for food packaging applications. Food Research International, 42(9), 1240-1253.

[11] Pereda, M., Ponce, A. G., Marcovich, N. E., Ruseckaite, R. A. and Martucci, J. F. 2011. Chitosan-gelatin composites and bi-layer films with potential antimicrobial activity. Food Hydrocolloids, 25(5): 1372-1381.

[12] Gómez-Estaca, J., López de Lacey., A, Gómez-Guillén, M., López-Caballero, M. and Montero, P. 2009. Antimicrobial activity of composite edible films based on fish gelatin and chitosan incorporated with clove essential oil. Journal of Aquatic Food Product Technology, 18(1-2): 46-52.

[13] Kulkarni RR, Patki PS, Jog VP, Gandage SG and Patwardhan B. 1991. Treatment of 
Maté, J.I., 2014. Antimicrobial efficiency of edible coatings on the preservation of chicken breast fillets. Food Control, 36(1), pp.69-75.

[31] Jouki, M., Yazdi, F.T., Mortazavi, S.A., Koocheki, A., Khazaei, N. 2014. Effect of quince seed mucilage edible films incorporated with oregano or thyme essential oil on shelf life extention of refrigerated rainbow trout fillets. International Journal of Food Microbiology, 174:88-97

[32] Sallam, K.I., Samejima, K. 2004. Microbiological and chemical quality of ground beef treated with sodium lactate and sodium chloride during refrigerated storage. LWT-Food Science and technology, 37(8):865-871

[33] Sharaf, A.M. 2006. Chemical characteristics of ostrich meat in comparison with beef and chicken meats. Egypt Journal of Appl. Science. Vol 1,pp:569-580

[34] Pranoto, Y., V .M. Salokhe and S .K., Rakshit .2005 .Physical and antibacterial properties of alginate-based edible film incorporated with garlic oil .Food Research International, 38: 267-272.

[35] Alizadeh, V., Barzegar, H., Nasehi, B. and Samavati, V., 2017. Characterization of physical and antimicrobial properties of chitosan edible films containing Pistacia atlantica gum essence. Journal of Iranian food science and technology, 13(4): 584-593, [Persian]

[36] Hosseini, S. M. H., Razavi, S.H., Mousavi, S.M.A (2009). Antimicrobial, physical and mechanical properties of chitosan-based films incorporated with thyme, clove and cinnamon essential oils. Journal of Food Processing and Preservation. 33. 727 - 743. [Persian[

[37] Ahmad M, Benjakul S, Prodpran T, Agustini TW. 2012. Physico-mechanical and antimicrobial properties of gelatin film from the skin of unicorn leatherjacket incorporated with essential oils. Food Hydrocoll , 28:189-99

[38] Mohammadi, R., Yadgari, M., Moatar, F. And Shams, M., 2006. Antifungal activity of boswellia serrata essential oil against fluconazole-resistant and susceptible isolates of candida albicans. Journal of isfahan university medical science, 24(82): 30-36,
Technology, 41: 1733-8.

[22] Ahmadabad, M.K., Rezaei, M. and Ojagh, M., 2012. The effect of ascorbic acid combined with whey protein coating on the shelf-life of rainbow trout stored at refrigerator temperature: microbial and chemical analyzes. Iranian Journal of Nutrition Sciences \& Food Technology, 7(3), pp.69-78.[Persian]

[23] Behbahani, B.A. and Fooladi, A.A.I., 2018. Shirazi balangu (Lallemantia royleana) seed mucilage: chemical composition, molecular weight, biological activity and its evaluation as edible coating on beefs. International journal of biological macromolecules, 114, pp.882889.

[24] AOAC (1995): Official Methods of Analysis of AOAC International, 16th ed., P. cunniff, Arlington, Virginia. USA.

[25] Brink, I., Šipailienè, A. and Leskauskaite, D., 2019. Antimicrobial properties of chitosan and whey protein films applied on fresh cut turkey pieces. International journal of biological macromolecules, 130, pp.810-817.

[26] Vejdan, A., Ojagh, S. M., Adeli, A., Abdollahi, M. 2015. Preparation and characterization of the physical and mechanical properties of agar/fish gelatin bilayer films for food packaging. Journal of Fisheries Science and Technology. 4(3):133147. [Persian]

[27] Seydim AC, Sarikus G. Antimicrobial activity of whey protein based edible films incorporated with oregano, rosemary and garlic essential oils. Food Res Int 2006: 39(5): 639-44.

[28] Alizadeh Behbahani, B., Tabatabaei Yazdi1 F, Shahidi, F., Mortazavi, S.A., Mohebbi, M. 2017. Investigation of Chemical Compounds and Antibacterial Activity of Tarragon (Artemisia dracunculus) Essential Oil on Some Pathogenic Bacteria In Vitro. Qom University Medical Science Journal, 11(9):42-51, [Persian]

[29] Lillard HS. 1988. Comparison of sampling methods and implications for bacterial decontamination of poultry carcasses by rinsing. J Food Prot, 51: 405-408.

[30] Fernández-Pan, I., Carrión-Granda, X. and 
characteristics of beef patties during refrigerated storage. J Agric Food Chem . 49: 919-25.

[43] Kostaki M, Giatrakou V, Savvaidis IN, Kontominas MG. 2009. Combined effect of MAP and thyme essential oil on the microbiological, chemical and sensory attributes of organically aquacultured sea bass (Dicentrarchus labrax) fillets. Food Microbiol 26: 475-482

[44] Lu F, Liu D, Ye X, Wei Y, Liu F.2009. Alginate-calcium coating incorporating nisin and EDTA maintains the quality of fresh northern snakehead (Channa argus) fillets stored at $4{ }^{\circ} \mathrm{C}$. J Sci Food Agric; 89: 848-54.

[45] Behbahani, B.A., Shahidi, F., Yazdi, F.T., Mortazavi, S.A., Mohebbi, M. 2017. Use of Plantago major seed mucilage as a novel edible coating incorporated with Anethum graveolens essential oil on shelf life extension of beef in refrigerated storage. International journal of biological macromolecules, 94, pp.515-526.

[46] Ojagh, S.M., Rezaei, M, Razavi, S.H., Hosseini, S.M.H., 2010. Effect of chitosan coatings enriched with cinnamon oil on quality of refrigerated rainbow trout. Food Chemistry; 120:193-198. [persian]

[39] Mothana, R.A., Hasson, S.S., Schultze, W., Mowitz, A. and Lindequist, U., 2011. Phytochemical composition and in vitro antimicrobial and antioxidant activities of essential oils of three endemic Soqotraen Boswellia species. Food chemistry, 126(3), pp.1149-1154.

[40] Rashidimehr, A., Fazlara, A., Zarei, M., Pourmehdi, M., Noshad, M. 2019. Evaluation of thyme (Zataria Multiflora Boiss) and cumin (Cuminum cyminum) essential oils effects on the shelf life of optimized burgers with surimi. Journal of food science and technology, 90(16): 187-200

[41] Hayouni EA, Chraief I, Abedrabba M, Bouix M, Leveau JY, Mohammed $\mathrm{H}$ and et al. 2008. Tunisian Salvia officinalis L. and Schinus molle L. essential oils: Their chemical compositions and their preservative effects against Salmonella inoculated in minced beef meat. International Journal of Food Microbiology, 125: 242-251.

[42] Giroux M, Ouattara B, Yefsah R, Smoragiewicz W, Saucier L, Lacroix M. 2001. Combined effect of ascorbic acid and gamma irradiation on microbial and sensorial 


\title{
Survey of antimicrobial gelatin-frankincense (Boswellia carteri) bilayer edible film incorporated with ascorbic acid and Hyssopus officinalis essential oil on ostrich fillets shelf life at refrigerator temperature
}

\author{
Pirnia, M. ${ }^{1}$, Tabatabaee Yazdi, F. ${ }^{2 *}$, Mortazavi , S. A. ${ }^{3}$, Mohebbi, M. ${ }^{4}$ \\ 1. Phd Student of Food Microbiology, Department Of Food Science and Technology, Faculty of Agriculture, \\ Ferdowsi University of Mashhad-Iran \\ 2. Professor in Food Microbiology, Department of Food Science and Technology, Faculty of Agriculture, Ferdowsi \\ University of Mashhad -Iran \\ 3. Professor in Food Science and technology, Department of Food Science and Technology, Faculty of Agriculture, \\ Ferdowsi University of Mashhad -Iran \\ 4. Professor in Food Science and technology, Department of Food Science and Technology, Faculty of Agriculture, \\ Ferdowsi University of Mashhad -Iran
}

(Received: 2019/10/15 Accepted:2019/12/11)

Ostrich fillets is highly edible and one of most healthy and the least fat red meat samples. Due to carcass contamination along the slaughter chain, it becomes corrupted by the growth of meat microorganisms during storage. Being biodegradable, edible and efficient have caused edible films to be widely investigated and used as a good replacement for synthetic materials in packaging of food products. In this study a gelatin/frankincense (G/F) bilayer film was produced from gelatin and frankincense monolayers using the casting method in two phases. This research investigated antimicrobial activity of various concentrations of acid ascorbic (0,1\% and 2\%) and Hyssopus officinalis oil (0, 0.75\% and $1.5 \%)$ in edible bilayer gelatin/frankincense against Staphylococcus aureus, Bacillus cereus, Escherichia coli and Pseudomonas aeroginosa. on the other hand, effect of edible film was evaluated on microbial and chemical properties of ostrich meat for 12 day at refrigerator temperature. Diameter of inhibition zone showed that Staphylococcus aureus and Pseudomonas aeroginosa were most sensitive and resistant bacteria respectively. Compared with control sample, two treatments $(\mathrm{G} / \mathrm{F}+2 \% \mathrm{AA}+0.75 \% \mathrm{HO}$ and $\mathrm{G} / \mathrm{F}+2 \% \mathrm{AA}+1.5 \% \mathrm{HO}$ ) decreased total viable count, psychrophilic and lactic acid bacteria significantly ( $\mathrm{p}<0.05)$. The result also showed with addition Hyssop oil and ascorbic acid, $\mathrm{pH}$ and peroxide values notably reduced compared with pure edible film (without oil and acid $)(\quad(p<0.05)$. The gelatin/frankincense films enriched with essential oil and vitamin $\mathrm{C}$ delayed tissue breakdown, and increases the $\mathrm{pH}$ by reducing the bacterial growth. Therefore, antimicrobial edible film containing Hyssop oil and vitamin $\mathrm{C}$ as an economical and biodegradable coating has a good potential for increasing the shelf-life of ostrich meat at the refrigerator $(4 \dot{\mathrm{C}})$ temperature.

Keywords: Bi-layer edible film, Frankincense (Boswellia carteri), Hyssopus officinalis essential oil, Antimicrobial activity, Ostrich fillets

\footnotetext{
${ }^{*}$ Corresponding Author E-Mail Address: tabatabai@um.ac.ir
} 